\title{
Parent-Child Communication and Self Concept among Malays Adolescence
}

\author{
Asbah Razali ${ }^{1}$ \& Nur Azah Razali ${ }^{2}$ \\ ${ }^{1}$ University of Malaya, Malaysia \\ ${ }^{2}$ National University Malaysia, Malaysia \\ Correspondence: Asbah Razali, Department of Anthropology and Sociology, Faculty of Art and Social Sciences, \\ University of Malaya, 50603 Kuala Lumpur, Malaysia. Tel: 60-17-235-7085. E-mail: asbahrazali@um.edu.my
}

Received: May 13, 2013 Accepted: June 17, 2013 Online Published: August 30, 2013

doi:10.5539/ass.v9n11p189 URL: http://dx.doi.org/10.5539/ass.v9n11p189

\begin{abstract}
This research was conducted to determine the relationship between children's communication with their parents and self concept among Malay adolescence. The Questionnaire of Communication Exercise for Teenagers (1971) was used to measure the level of communication between child and parents whiles the second questionnaire, Harter Self Perception Profile for Adolescents Scale (1986) was used to measure the child's self concept. This quantitative descriptive study selected 300 consist adolescence aged 15-16 years. Random sampling was used to select the sample. The results showed that there has a relationship between children communication with parents and adolescent self concept. According to this study, the results of the study seem to describe that Malay society is still maintaining the societal pattern that is collectivistic in nature. What is most interesting is that the results of the study also describe how Malay society still maintains the traits of societal life that emphasize on harmony even in communication. This is because Malays have their own method in conveying their thoughts. This proves that families in Malay society place more importance in familial relations, family gatherings, cooperation during feasts, sharing and emphasize on mutual rights in all aspects of life.
\end{abstract}

Keywords: communication, self concept, gender, adolescents, malay's value

\section{Introduction}

The relationships of self-concept with various aspects have been extensively studied. Among them were study between self-concept and family support and many study have already been conducted on these variables in and outside of the country. As of today, there are few studies that have been conducted to identify family support and its relation to various other aspects such as academic achievement, parental parenting style, parental behavior and children, personality and interpersonal skills, motivation, conflict and life stress, satisfaction and well-being, family structure, parental involvement in decision-making for the kids, family size (number of siblings), educational level and occupation of parents, quality of love, criticism and praise, depression, child behavior-children, parental control of children and much more (Yusof, 2004).

Many studies in the West also show that there is relationship between self-concept and family support among teenagers. Healy \& Broner (1936) is one of two early researchers who have an opinion that the relationship between parents and children is very important in determining the formation of a healthy self amongst children. This is because teenagers are said to spend more time with his family than being outdoors.

In Malaysia, there are some researchers who have conducted studies related to self-concept and family support. This includes research conducted by Sarina Tengku Band (1999), which has seen the influence of family and self-concept among high school students; Montoyo (2007) examined the relationship between family support and self-esteem among outstanding students; relationship of family support and parental involvement (Abdullah Al-Hadi et al., 1993); motivation of parents and children (Maznah \& Zuraini, 1993); study of family environment, family relationships and family size (Gunasekaran, 2003); physical intimacy family, social support, intimacy and relationships lasting (Amer, 2004), and the influence of parental control (Azizi, 2005; Ray, 2004) as well as the attitudes and behaviors of parents (National Institute of Child Development, 2004).

One of the dimensions measured in discussing aspects of family support is communication between parents and children. There has been little study conducted locally regarding communication. Among them is a study 
conducted by Tengku Sarina Band (1999) related to the influence of the family in terms of interaction and communication, relationship parents and their children as well as problems and children in the town. While Noor Azam (2003) studied about family communication disorders and their children. Additionally, Kamarulzaman (2002) researched on communication patterns and parent-child made up of disabled children and disabled and Mohd Talib (2006) studied communication among families of drug addicts and non-addicts. Clearly, there are many more aspects related to communication among Malay youths who have yet to be explored. Therefore, this study is the first attempt to examine the relationship between family support in terms of communication and the formation of self-concept among Malay youth specifically. In summary this study will be carried out trying to find out whether family support in terms of communication can influence the formation of self-concept of children. In addition, demographic factors (gender) are also considered as variables that can influence the self-concept among children.

Most Western studies have shown both these variables are capable of relating positively (Cheng \& Furham, 2003; Coopersmith, 1980; Shields \& Clark, 1997; Harrist, 1998; Horlock, 1973; Thames, 2004; Sillars, 2005; Wright, 1992: Young \& Shelley, 1997) and there is no relationship between the two variables used (Demo \& Small, 1987; Roberts, 1993). However, researchers in the West have seen the communication of children and parents from the community angle that adopting individualistic than collectivistic concept. Furthermore, the studies of these variables in collectivistic societies are lacking. So far there are some researchers who tried to examining the relationship between parental communication, children and self-concept among collectivistic society such as Greenberger et al., (1996); Rhee et al., (2003). Thus, the researchers feel there should be further research to identify the actual pattern of relationships between variables among parents and children who are ethnic Malays.

This is because, according to Teo (1998), in his study says that the Malays have higher collectivistic nature compared to the Chinese and Indian communities. In fact, according to Hashim (1994), included in the collectivistic nature of family relationships and communication between parents and children. This shows that the Malay community practices reciprocal communication between mother, father and their children through the process of socialization that has persisted since the children were young till adulthood. This situation shows that communication is very important for the Malay community. Good communication between parents and children is crucial in the Malay community because they look up to the members of the community who have such traits. The Malays are experiencing problems in communication and does not comply with the orientation of the parental socialization and children will be stigmatized by society.

In fact, children who behave indecently, does not listen to advice and order a parent, do not look at their mother, father or anyone else during the communication will be regarded as disrespectful and violates the values and norms of the society (Syed Hassan, 2004) . What's more, the Malays stick to Asian values and keep good manners and politeness when communicating with older people (Wan Kadir, 1994). Could it be that the communication between parents and children can enhance children's self-concept? When Asian values and modesty preserved, communication would run better thus leading to a positive attitude in the children themselves. Researchers feel there should be a specific study to measure whether there is relationship between parent child communication and self-concept among Malay children.

In addition, this study will also try to identify the extent of the authorization state by Young \& Shelley, (1997) in relation to the high correlation between child communication and parental and adolescent self-concept among collectivistic Asian society. This study also identifies whether the relationship between the two variables is significantly related among Malay youth is indeed considered a collectivist nature by researchers in the West. Although there are studies conducted in the collectivistic society as researchers mentioned earlier, but it was different with Malay youth. For example, a study conducted by Young \& Shelley (1997) examine the relationship among Korean adolescents while this study attempted to examine the relationship between these variables for the Malays and adolescents aged 15-16 years. In other words, this study will be conducted to identify whether children's communication with parents is significantly interconnected among the Malay community is indeed considered collectivistic society in the West.

This study will try to see how parents communicate with their children. According to Endicott \& Loissis (2005) there is a difference in communicating between mother, father and children. Children are more easily able to express themselves and their problems with parents without the involvement of their father. In fact, fathers are said to be more assertive in making decisions in the family. Communications of the children and parents may be able to have an impact on children because most children's self-acceptance depends on the response and feedback they get from people around them. However, not all previous studies confirm such expectations. Following the opinion and the results of past studies, communication confusion about the kids and parents. Is there a difference between a child's communication with thier mother and father respectively? Are the results of 
this study as the results found by researchers in the West? This question arises because of the lack of studies looking at the differences in communication between parents and children in Malaysia today. Therefore, this study will try to submit difference may reflect the communication between parents and children more clearly.

Moreover, according to Wood, (2001), men are more suited to masculine characteristics such as less emotional, powerful, aggressive and more dominant than females who tend to have feminine traits as more emotional, friendly, and submissive. If you look at the aspects of learning in school, the teachers also tend to give students the opportunity to express views of men as compared to girls who are not given the same opportunity. This will build a high self-concept in boys themselves. For example, they are more confident and have a wonderful personality. Instead, for the girls, they still maintain their shyness causing less confident and be passive (Wan Kadir, 2003). This is what causes the researchers want to know more, does the gender differ significantly or not? Still there has not been a study conducted to see gender differences on self-concept among Malay youths so far. Therefore, the researcher felt the need to look at the level of self-concept among adolescent boys and girls whether both sexes has significant differences in self-concept, or vice versa? Hence this study is an attempt to see whether researchers demographic factors (gender) influence the self-concept among Malay youths.

\section{Literature Review}

\subsection{Communication between Parents, Children and Self Concept: Western Studies}

So far, there have been many studies conducted by Western and Malaysian psychologist in relation to the variables of communication between parents and children with self-concept of children. However, there is still no consistency in the findings between the two variables. This is because, there are previous researchers saying that there is no relationship between the two variables used. The following describes the findings of past studies that have been found by previous researchers beginning with the findings by Western researchers and followed by researchers in Malaysia.

Hurlock (1973) have examined the relationship between communication children and parents, self-concept and self-concept demographic factors. A total of 284 rural youth have filled in a questionnaire and the results showed that there is a significant relationship between the two variables of self-concept. Barnes \& Olsen (1985) also conducted a study on 400 adolescents (200 males and 200 females) in connection with the communication between parent-child and the child's self-concept. He had used Rosernberg Self Esteem Scale to show a significant relationship between the two variables. Therefore, they argue attention and input from parents is important to develop self confidence in children. This indicates that the positive communication between parent and child will increase adolescents self concept.

Similarly, the study conducted by Wright (1992) on love, attention and advice from parents as predictors for the formation of positive self-concept showed that there is a strong relationship between the two variables used. He had used the Piers Harris Children's Self Concept as a measure in this study. He also said that the communication of children and parents is very important in determining the child's self. Children who communicate with their parents will know their role, advantages and disadvantages of self, more disciplined and responsible compared with children who have communication problems with their parents. These children are likely to have a passive trait, not disciplined and not responsible. Therefore, he felt that parents should provide support, encouragement and guidance to ensure that children are not diverted towards negative self-concept formation.

In addition, a study conducted by Shields \& Clark (1997) found that the relationship between communication, self-concept and aggressive behavior has a very high correlation. Similarly, a study conducted by Harrist (1998) showed that children who are unable to communicate well with their parents showed delinquency problems in adolescents. A total of 290 adolescents aged 16-17 years participated in this study. They also found that parents' inability to communicate with their children especially teenagers produce aggressive adolescents. This indicates that these variables are able to communicate positively with children's self concept.

There are several other studies that also examine the relationship between parental communication and children's self concept. For example, Levitt (1998) was interested to know whether there is a relationship between communication problems of children and parents, stress, emotional disturbance and its relation to the decline of urban adolescent self esteem. A total of 436 adolescents (222 males and 224 females) aged around 16-18 years was taken as respondents. Results of their study showed that effective parent communication not only increases the self-concept of children, but can also affect all aspects of the self that is in the children, including motivation, attitudes, patterns of life and emotional well-being of their children. This indicates that the communication of the children and the parents are not universal to be associated with the formation of self-concept only. In fact, the communication of children and parents also influence academic achievement, satisfaction and well-being of the children and also can prevent children from being stressed and depressed. 
Thames (2004) also conducted a study on communication of parents and children, and religious self-concept. A total of 2080 young people aged 14-18 years (1002 men and 998 women) were taken as respondents. The results showed a positive relationship between parental communication and children with children's self-concept among Israeli teenagers living in the school hostel. This shows that both these variables are interconnected with each other. Feedback received by the parents is very important in cognitive and social development of the next to form an opinion about them overall comparison to those who are affected by their environment such as their peer (Millet, 1995).

In addition, Cooper (1982) also examine the relationship of children who have parents who communicate positively and negatively on their self-concept. Respondents consisted of 331 children (119 boys and 212 girls), aged between 10-12 years. The study found that children who have parents who are often positively communicate closely forms a positive self-concept in themselves. In contrast, children who have parent communicate with them negatively cause less confident in themselves and do not have many friends. Therefore, the research shows that communication between parents and children have a strong relationship with the self-concept of children. He added that the positive relationship is due to focus given to children by parents when they are in primary schools as they still are dependent on their parents, particularly in developing their self-confidence.

Apart from using a sample of adolescents and children, there are also some researchers who examine the relationship between these two variables in adults. For example, Cheng \& Furnham (2003) in his study also looked at the relationship between family, self-esteem and psychological well-being in adults. A total of 293 respondents completed the survey were randomly selected. The study found that parents who communicate well to children since childhood will enable the children to increase self concept during adulthood. Second, negative psychological decline when children reach adulthood because they have begun to carry out responsibilities such as finding a job, get married, have their own income and have a family. Third is the love of parents since childhood brings advantages and benefits to the children in the long run. All three of these findings indicate that the two variables are positively interrelated.

Robert (1993) also examined the relationship between communication children and parents, demographic factors and self-esteem, and life satisfaction among adults. A study conducted in Southern California involving 293 adults (152 males and 141 females). He has used Rosernberg Self Esteem Scale as a measure in this study. The study found that parents are communicating with their children and give affection since small children are still able to increase the level of self-esteem when their children are young. However, the study found conflicting results with the findings of previous researchers. He found no relationship between parental communication and children with high levels of self esteem in adults. They felt that this difference occurs due to the need of adults have no communication with both parents compared with children and adolescents. This is because, when the children have grown up, they have other responsibilities such as having a career and married life. This suggests that the relationships between these two variables are still inconsistent even when using the same age level.

However, there are also some Western researchers say parents communication is not a major factor contributing to the formation of a positive self-concept among children. This means that there are other factors that are more powerful. For example, a study conducted by Harter (1998) shows that the strength of relationship between the two variables (communication parents, children and self-concept) is only at a moderate level $(r=0.37)$. A total of 180 respondents aged between 13-14 years participated in this study. The study found that parental communication with children is not a major factor to the formation of self-concept of children. In fact, he said, the youth at an early stage will shift attention to their peers because they feel more comfortable to express their problems with friends than with parents. However, children are not able to communicate well will result in a negative self-concept formation. Western researchers have found that most children like this is likely to face serious problems such as emotional problem, deviant behavior, intellectual problems, truancy, alcohol, drugs, pregnancy out of wedlock and suicide (Emery, 1998; Felson, 1989; Hoffman, 2002; Mc Coy, 1986; Moore, 1981). This would explain that although parent's communication is not a major factor in the development of a positive self-concept among children, but children still need parents for support, suggestions and advice so as not to fall into the social problem.

This argument was further agreed by Small (1988). He had studied the relationship between family communication and child self consept and demographic factors among urban youth in Minnespolis. A total of 598 young people aged 16-17 years were the respondents. He has been using the Piers Harris Children's Self Concept as a measure in this study. Studies have reported that there is a moderate relationship between parental communication and children with high levels of self-esteem of children. According to him, this simple relationship caused by most parents in the city are not concerned about quality time and relationships with the 
children cause the children have a negative assessment of their parents. This in turn leads to low self esteem in the children themselves.

Apparently, the findings on children's communication with parents and self-concept so far found no consistency. This is because, there are some researchers who say there is a positive, negative, and also the availability of a simple relationship. Simple relationship is seen because of other factors that also affect the self-concept of children as well as communication between the mother and the father. This question leads to the need to conduct a study of the relationship between children's communication with parents and self-concept so that this issue can be clarified further. With this, the felt need a study to look at how relations between the two variables in the Malay community.

In addition, previous studies also found that the Asian community of communication varies with the form of communication within Western society. For example, a study conducted by Young \& Shelley (1997). They conducted a study on 70 high school youth in the city related to communication between Korean parents and their children. The findings found that communication parents and children have a high correlation to the youth in collectivistic societies than adolescents in individualistic societies. According to them, parent's communication with children in Asia and the West are different due to the different culture of the two communities. Most kids are still does not practice the concept to be honest with parents even more so when it involves things that are considered sensitive, such as relationships with friends of the opposite sex, things associated with love and sexual relationships. This is what distinguishes between Asian and Western societies. Communication between parents and children in the West do not restrict the children to share their problems and sensitive matters in Western parents give give freedom to their children to decide for example in love and sexual relationships. This is what distinguishes between collectivistic and individualistic society. In fact, Wong \& Ollendick, (2001) believe that the more collectivistic society emphasizes communication of children and parents focused on advice and regulation to keep family relationships and individualistic society that does not give emphasis on the relationship with family members and the community around them.

Rhee et al., (2003) also sees patterns of communication and self in Asian and Caucasion adolescents who immigrated to America. Their study aimed to determine the degree of openness of communication with parents and concept among the two groups of teenagers. In overall, it showed that more Asian youth being shy and have difficulty to communicate with their parents, especially matters related to the problems they face compared to Caucasion adolescents. The findings also indicate, Asian teen finds it difficult to communicate with their parents because they think that their parents are not good listener, sometimes degrading them and feels that they cant be trusted. Asian youth are found to have negative interpersonal problems, disappointed in family support and difficult to get reactions from the community. This gives the effect of a negative self-esteem.

Asian teen has difficulty communicating with their parents. The difficulty communicating is more clear with their father because of the Asian community, the culture are more in favor of men, and all results are determined by a father who is considered as the head of the family. More specifically, the communication still exists a gap between parents and children because parents have more power in a patriarchal system. This is in contrast with the more Caucasion teenage openness when communicating with their parents. Good communication between parents and children can boost self-esteem because the child support from their parents (Zajonc \& Mullally, 1997).

In addition, a study conducted by Greenberger et al., (1996) also found that there are differences on parental communication and children of teen in West compared with the Asian community. According to them, communication between parents and children in the West and Asia vary due to differences between the cultures of the two continents. Communication between parents and children in the West more open and parents are not limiting the children to share their problems and express their views. Western values allow children to freely communicate with parents in all aspects. While for the Asian youth, parent communication and the kids are not open and friendly. For Asian youth also, they still maintain traditional practices that restrict family communication only to things that are important only. Open communication between parents and children is still strong in Asian community and the liberal culture is practiced in the West is certainly not acceptable in the Asian community. This communication shows parents and children are very strong relationship with the community individualistic than collectivistic societies that restrict communication of parents and children on sensitive matters.

In fact, a study conducted by Sillars (2005) showed that parental communication and children are still at a high level since the Asian community is still holding fast to the traditions and culture that has been practiced since time immemorial. Still strongly held values, including respect for parents, do not discuss sensitive matters, keep 
the faith, speaking with a gentle tone, maintain a good relationship with their parents and relatives and so on, where it is associated with the values adopted in a collectivistic society. Previous studies mentioned earlier clearly shows that the Asian community of communication varies with the form of communication for the West. However, whether these differences also exist in the Malay community? These questions will be answered by the researcher in this study.

It can be seen most of the previous studies mentioned earlier tend to incorporate parents in their study. Yet, it is clear that there are differences in communication between parents and children. For example Endicott \& Loissis (2005) also conducted a similar study, but their study did not compare between the two communities. They have used a sample of 57 pairs of parents and teenagers (14 mother-son pairs, 16 mother-daughter pairs, 15 father-son pairs, 12 father-daughter pairs). Youth participants are in the age range of 13-16. The results showed that there are differences in communication between the mother and father of the children. Clear difference was seen between mother and son that the mother of the son are more likely to give up hope. This is because, to all the mothers in this study assume more clever son will replace the father independently and as head of the family. In addition, parents often give freedom to their son and this tendency makes males have a higher self concept than their daughter. While between mother and daughter, they are fmore friendly in communicating, sharing their problems and opinions. For fathers, the communication pattern is similar between boys and girls. Fathers tend to give attention to his son and daughter at the same rate.

Gecas \& Schwalbe, (1986) also see the difference in the means of communication between parents and children in Australian adolescents. This study was conducted with 105 adolescents Brisbane (56 males and 49 females) aged 15-18 years using a Parent-Adolescent Communication Scale (PACS). The results showed that there are differences in communication between mothers and fathers with their children. Children more easily express themselves and their problems with parents without the involvement of the father. This is because the father did not have enough time to spend with their children than mothers. In fact, the father said to be more assertive in decision-making within the family. However, these studies only look at Western society without focusing on Asia, especially the Malay community. Does this also exist among the Malays? Its have differential way parents communicate with their children in the Malay community? This study also shows the advantages that have never been found in the Malay community because this study will look at ways of communication parents separately.

\subsection{Malaysian Studies}

There are some researchers who have conducted studies related to the two variables. Among them is a study conducted by Abdullah Al-Hadi et al., (1993) related to the relationship between communication and interaction on the level of parental self-concept children at a school in the town. A total of 233 adolescents (89 males and 144 females) filled in the questionnaire and he had used Coopersmith Self Esteem Inventory (1967). The study found that there was a significant relationship between communication and interaction of parents and children. The study also found that parents assess children in a positive way, giving words of encouragement and stimulation to children show a positive correlation to the self-concept of children.

A study conducted by Siti Nor (1993) on family factors with self concept and immoral behavior among adolescents in Felda. A total of 788 adolescents (359 males and 429 females) early stages of adolescence were taken as respondents. Their average age is in the range of 13-15 years. The findings once again found communication with parents have a very strong relationship with the formation of self-concept of children. Additionally, immoral behavior is also found associated with parental communication style. This shows the three variables used are interconnected by communication of parents and their children. In fact, according to him, good communication between parents and children can reduce conflict between parents and children, improve academic achievement and to prevent children from behaving like a delinquent. Feedback given by parents can give children confidence and act according to the values and norms of the society so that they do not feel left out of society.

However, a study conducted by Tengku Sarina (1999) is seen as opposed to the study that have been discussed earlier. The study is focused on the influence of family communication and its relationship with urban adolescent self-concept. He has used a total of 40 students (20 male and 20 female) from a school in town. The study found that communication between parents and children does not affect the self-concept of children. According to him, different communication will give different effects on the formation of self-concept of children.

Chiam Heng Kheim (1982) also conducted a study on the closeness of parents and children and to see whether communication can be a predictor to the form high self esteem with children. He had taken 144 adolescents using questionnaires Piers Harris Children's Self Concept to test both these variables. The study found that there was no strong correlation between the two variables. Poor parents communicate with their children, and less 
friendliness causes children to lose respect for parents. The study also found a lack of communication by parents will also cause the probability of children to be less optimistic, less confident and always feel anxious and doubtful - free to do anything.

In conclusion, the average results of past studies so far seem to show positive results in the relationship between the two variables (communication between parents and their children with the self-concept). However, there was still disagreement or difference in the findings in the study of parental communication and children. This is because there are researchers who say there is relationship between the two variables (Abdullah Al-Hadi et al., 1993; Siti Nor, 1993) and vice versa (Chiam, 1986; Tengku Sarina, 1999). Of course there are differences between mother and child communication; and fathers and children communication as has been found by researchers in the West. Are the results of this study will be the same as the results obtained by most Western researchers or vice versa? Therefore, this study will look at communication between parents separately so that the results obtained are more obvious. This is because, until today still there is no researchers in Malaysia to examine the relationship between these variables separately.

In addition, most researchers in Malaysia are not the perception of parents and their children and children's perceptions of their parents. This is because, according to Western researchers, there are differences in the perception of both parties that between parents and children. Therefore, this study that will be carried out will see more clearly whether there are differences in perception among parents and children among the Malays that the findings are not biased. With this, the researcher felt that there should be further research to look at all aspects of the communication variables in the children and parents in the Malay community more clearly.

\section{Method}

The instrument used in the present study was structured and self-administered survey questionnaire. Harter Self-Perception Profile for Adolescents Scale (Harter, 1986) and Inventory Communication Exercise For Teenagers (CET) has been usedin this study. This questionnaire is a comprehensive survey tool and can be used to measure all aspects of communication between children and parents, and self-concept (Amato, 1986). In addition, the questionnaire also contained demographic questions include gender. Inventory Communication Exercise For Teenagers (Beinvenu, 1972) was used to examine the relationship between child communication and parent. A total of 30 items related to communication have been selected to test the communication between parents and children of 15 items for the father-child communication and 15 items for the mother-child communication. This questionnaire is used to examine the relationship between communication between parents and their children the next to know whether the communication of children and parents influence an adolescent self-concept or not. CET is scored using Likert scale with one representing "strongly disagree", two represent "do not agree", three represents "not sure", four representing "disagree" and five representing "strongly agree" for positive items. For negative items, the Likert scale is still five options but it upside down with the one representing "strongly agree", two representing "agree", three represents "not sure", four representing "disagree" and five "strongly disagree ". Score high marks is that they have good communication with both mothers and fathers. However, the reliability of this test through the Malay language version is a little low, Alpha $(\alpha)=0.67$ however, this tool is still stable and usable.

\section{Results}

Pearson correlation test is used to examine the relationship between children's communication with parents and nine aspects of children's self-concept. Qualitative analysis is also reported in this chapter. 
Table 1. Mother, father and child communication and self-concept

\begin{tabular}{lll}
\hline Self Concept Variable & Mother's Communication & Father's Communication \\
\hline Scholastic Competence & $.042^{*}$ & $.035^{*}$ \\
Social Competence & $.010^{*}$ & $.032^{*}$ \\
Athletics Competence & $.049^{*}$ & $.014^{*}$ \\
Physical appearance & $.025^{*}$ & $.049^{*}$ \\
Work Efficiency & $.017^{*}$ & $.041^{*}$ \\
Romantic Appeal & $0.32^{*}$ & $.049^{*}$ \\
Moral Behaviour & $0.30^{*}$ & $0.19^{*}$ \\
Friendship & $.029^{*}$ & $.021^{*}$ \\
Overall Self Esteem & $.063^{*}$ & $.047^{*}$ \\
\hline
\end{tabular}

According to Table 1.1, there was a significant relationship between mother and child communication with all aspects of the self-concept. Scholastic competence $(\mathrm{r}=.042)$, social competence $(\mathrm{r}=.035)$, athletic competence $(\mathrm{r}=.010)$, physical appearance $(\mathrm{r}=.032)$, work efficiency $(\mathrm{r}=.049)$, romantic appeal $(\mathrm{r}=.014)$, moral behavior $(\mathrm{r}=.25)$, close friendship $(\mathrm{r}=.049)$, and overall self esteem $(\mathrm{r}=.017)$. This means that there is a relationship between parent communication and self-concept of children. This explains the mother and child communication interconnected with each other.

Instead, the father and child communication, there are eight aspects of the self-concept of interconnected scholastic competence $(\mathrm{r}=.041)$, social competence $(\mathrm{r}=.032)$, athletic competence $(\mathrm{r}=.049)$, physical appearance $(\mathrm{r}=.030)$, work efficiency $(\mathrm{r}=.019)$, romantic appeal $(\mathrm{r}=.029)$, moral behavior $(\mathrm{r}=.021)$, and overall self-esteem $(\mathrm{r}=.047)$. This means that there is a relationship between father communication and self-concept of children.

\section{Discussion}

\subsection{There Is a Relationship between Children Communication with Parents and Adolescent Self Concept}

Based on the correlation analysis carried out, the results showed that communication with her children and their parents showed a significant positive relationship with adolescent self-concept. This means that communication between children and parents have an influence on children's self-concept. This finding is in line with a number of previous studies (e.g. Young \& Shelley, 1997; Rhee et al., 2003) who found that children communication with parents has a relationship with their self-concept. This result indirectly shows view of life in particular Eastern tradition practiced by the Malay-conscious and emphasizes social relationships to develop their self-confidence. Furthermore, the self-concept of the children in collectivistic societies does not only depend on the characteristics of self and self performance but emphasized self-concept is related to the relationship with others. Typically, self-concept in Western society does not only depend on yourself but self-concept is formed as a result of interpersonal relationships and social context. Likely explanation to this situation can be seen that children need a mother and father to know the disadvantages and advantages of them. With this, no wonder there is a relationship shown by the Malay community in child communication and parental self-concept as concerned with aspects of the Malay community groups rather than individual interests.

In line with the findings, these findings also support several previous studies (such as the Thames, 2004 and Wright, 1992) which reported that children communicate with their parents will know their role, advantages and disadvantages of self, more disciplined and accountable than children who have communication problems with parents who tend to have a passive nature, undisciplined and irresponsible. The same is also recognized by Millet (1995) who found that a relationship exists between communication and parents of children with self-concept causes children to form their views on the whole self. Thus, children tend to use communication to get their views and support from their parents. Therefore, further exploration of children's communication links with parents and children self-concept should be expanded so that a more accurate answer can be obtained.

According to Fatimah (1995), parents are able to meet the individual needs of children as moral support and protection. This result is not surprising because the Malay community is already support to each other which is why self concept interconnected by communication of children and parents. Parental emphasis on the performance of children in their self concept. Integrity in the communication of children and parents can enhance 
their self-concept (Baldwin \& Hoffman, 2002). Thus, it is possible that communication links children and parents to improve self-concept because parents are always concerned about the child. In fact, usually all related to the self is related to an individualistic society. The results also seem to illustrate that the Malays are still maintaining the patterns of a collectivistic society.

Interestingly, the study also seems to reflect that the Malays are still maintaining the characteristics of life that emphasizes harmony even in communicating. This is because, the Malays have their own way when submitting opinion. If the parents do not agree with the opinion of the children, the children should respect the views of their parents. Furthermore, the Malay family is seen as a group of individuals living under one roof and is comparable with the one people living under the same sky. The diversity of individuals in the family an opportunity to communicate with family members so that the family relationship more closely intertwined. This proves that the family of the Malay community is more concerned with family relationships, family members gather each other, work together when there sharing a in all aspects of life (Syed Hassan, 2004).

\subsection{Limitation Study}

There are some limitations of the study have been identified in this study. The first is that this study used the questionnairs built from the West. Researchers feel better if the Malays have a set of likert-scale testing tool that examines self-concept for adolescents East as Western society. For example, relationships with others, family relationships, polite, respectful, courteous, and so on. Hence, it can be seen whether the major factor contributing to the increased level of self-concept of Malay youth through more clearly.

Second, as was mentioned earlier real, the question posed in the Harter Self Perception Scale may not compatible with the Malay culture and the possibility of these questions are not appropriate for teenagers in Malaysia. For example, in questions related to the Romantic Appeal as follows:

1) some teens feel that they are interesting and entertaining while out with their partner,

\section{BUT}

2) some teens feel doubt whether they are able to attract a mate.

In fact, Chiam (1984) says that:

"Behaviour has yet to be dating culture among young Malaysians, especially the rural youth. Normally, Malay teenagers still feel ashamed between friends of the opposite sex and be seen separating the Malay culture among the sons and daughters at home and at school. In fact, many girls refuse to cooperate with each other opposite sex. They also tend to prevent yourself from mixing with the opposite sex. This also forms a barrier to teens to be interested in each other."

In addition, limitations also exist in the questions related to the efficiency of the work. One of the characteristics in the questionnaire are presented in conducting self-concept part-time work. The problem that exists is that there are only very few Malay teenagers who have part-time jobs in rural areas. They only work to fill spare time in school holidays only. In fact, the phenomenon of teenagers working part-time and this does not exist in the Malay community in rural areas because they receive financial support from the government and persekolah. Perhaps the question and approach adopted by the West is not suitable for the Malay community especially for Malay youth.

Next, the researchers put forward four qualitative questions to find out the difference of communication between mothers and fathers, but researchers only use the 10 respondents only. Researchers feel that the most significant deficiency in the number of respondents is too little. Therefore, the findings can not be generalized to all adolescents to see the difference of communication children and parents in the broader context.

In fact, the researcher not involved and did not make their parents as part of the respondents instead researchers use only teenagers as respondents. Given these factors are not given emphasis and neglected in this study, the results of this research was still having its own limitations. Therefore, researchers feel the parents should be involved so that the findings are more accurate and the findings can be generalized more widely.

Subsequently, this study only sees only one culture of the Malay community. Because of this specific study on Malay youth in Malaysia alone, then this study may not be comparable with the findings of other countries are also engaged in different cultures. This is because, in Malaysia there are two main groups of teenagers teenage Chinese and Indian youth. Chances are, every culture different races cause findings also vary. Thus, as cultural factors are not given emphasis in this study, the results of this research were still having its own limitations.

Finally, the number of respondents used in this study $(n=300)$ is too small and not enough to digenalisasikan to all youth in Malay in Ticketing Reservation Systems. Therefore, the selection of respondents should be extended 
to all aspects of the review can be generalized. Although there are some limitations in this study, the researchers feel that this study will show an initial overview of the level of adolescent self-concept Malay and communication differences between children and parents in the Malay community. However, the issues that have been dealt with earlier, and further research should be highlighted from time to time should be carried out by future researchers.

\section{References}

Azizi, H. Y. (2005). Family: A Place for Cultivating Positive Attitudes and Behaviours. In Asian Social Psychology Conference, 25-29 July 2007, UMSSabah, Malaysia. (Unpublished).

Barber, B. K., \& Thomas, D. L. (1986). Dimensions of father's and mother's supportive behavior: The case for physical affection. Journal of Marriage and The Family, 48, 783-794. http://dx.doi.org/10.2307/352571

Barnes, H. L., \& Olson, D. H. (1982). Parent adolescent communication scale. In D. H. Olson et al., Family inventories: Inventories used in a national survey off a milies across the family life cycle, 33-48.

Beinvenu, M. J., \& Mc Clain, S. (1970). Parent Adolescent Communication and Self Esteem. Journal of Home Economics, 62(5), 344-345.

Bem, S. L. (1976, April). The Measurement of Psychological Androgyny. Journal of Consulting and Clinical Psychology, 42, 155-162. http://dx.doi.org/10.1037/h0036215

Burns, R. M. (1982). Child, family, community: Socialization and support. Fort Worth Hocourt Brace Javanorich College Publisher.

Byrne, B. M., \& Shavelson, R. J. (1996). On the structure of social self-concept for pre-, early, and late adolescents. Adulthood. Journal of Family Psychology, 7(1), 91-103.

Campbell, A., Converse, P. E., \& Rogers, W. L. (1976). The quality of American life. New York, Sage.

Carlson, R. (1971, October). Sex Differences in Ego Functioning: Exploratory Studies of Agency and Communion. Journal of Consulting and Clinical Psychology, 37, 267-277. http://dx.doi.org/10.1037/h0031947

Coughlin, J. P., \& Malis R. S. (2004). Demand/withdraw communication between parents and adolensecnt as a $\begin{array}{lllll}\text { correlate of relational satisfaction. Communication reports, } & \text { 17(2), } & \text { 59-71. }\end{array}$ http://dx.doi.org/10.1080/08934210409389376

Craven, R., \& Roche, L. (1995). The effect of gifted and talented programs on academic self concept: The big fish strikes again. American Educational Research Journal of Educational Psychology, 32(2), 285-319. Mind. New York: Basic Books. http://dx.doi.org/10.3102/00028312032002285

Cross, S. (1993). "It never struck me as female": Investigating men's entry into female dominated occupations. Journal of Gender Studies, 15, 35-48.

Eagly, A. H., Wood, W., \& Diekman, A. (2000). Social role theory of sex differences and similarities: A current appraisal. In T. Eckes \& H. M. Trautner (Eds.), The developmental social psychology of gender, 123-174. Mahwah, NJ: Erlbaum.

Eagly, A. H. (1987). Sex Differences in Social Behavior: A Social Role Interpretation. Hillsdale: Erlbaum.

Endicott, R., \& Loissis, P. (2005). Australian adolescent's perceptions of other parent: An analysis of parenting styles, communication dan feelings toward parents. Youth Studies Australia, (8), 24.

England, M. (2006). Masculine norms and the therapy process. In M. Stevens (Eds.), In the room with men (pp. 13-47).

Gecas, V., \& Seff, M. A. (1990). Families and adolescents: A review of the 1980. Journal of Marriage and the Family, 52, 941-958. http://dx.doi.org/10.2307/353312

Gilligan, C. (1982). In a Different Voice: Psychological Theory and Women's Development. Cambridge and London: Harvard University Press.

Gilligan, C. (1982). In a Different Voice: Psychological Theory and Women's Development. Cambridge and London: Harvard University Press.

Goddard, C. (1997). Cultural values and 'cultural scripts' of Malay (Bahasa Melayu). Journal of Pragmatics, 27, 183-201. http://dx.doi.org/10.1016/S0378-2166(96)00032-X

Gordon, T. (1981). Behavioral parent training. In A. S. Gurman, \& D. P. Kniskern (Eds.), Handbook of family 
therapy, 517-555. New York: Bruner/ Mazel.

Greenberger, E. (1996). Perceived family relationships and depressed mood in early and late adolescence. Comparison of European and Asian Americans. Developmental Psychology, 32, 707-716. http://dx.doi.org/10.1037/0012-1649.32.4.707

Harris, A. (1998). Communication development and disorders in African American children: Research, assessment, and intervention.

Harris, A., \& Lambert, S. P. (1991). Father, sons and daughters: Differential paternal involment in parenting. Journal of Marriage and the Family, 53, 531-544. http://dx.doi.org/10.2307/352730

Harris, R. J., Firestone, J. M., \& Vega, W. A. (2005). The interaction of country of origin, acculturation, and gender role ideology on wife abuse. Social Science Quaterly, 86, 463-483. http://dx.doi.org/10.1111/j.0038-4941.2005.00313.x

Harter, S. (1986). Developmental processes in the construction of the self. In T. D. Yawkey, \& J. E. Johnson (Eds.), Integrative Processes and Socialisation in Early to Middle Childhood. Lawrence Erlbaum, Hillsdale, NJ.

Harter, S. (1988). Manual for self-perception profile for adolescents. Denver, CO: University of Denver.

Harter, S. (1988). The self-perception profile for adolescents. Unpublished manual, University of Denver, Denver, $\mathrm{CO}$.

Harter, S. (1993). Developmental perspectives on the self-system. Socialization, personality, and social development, 4, 275-386.

Harter, S. (1993). Developmental perspectives on the self-system. In E. M. Hetherington (Ed.), Handbook of Child Psychology: Socialization, personality, and social development (Vol 4, pp. 275-386). New York: Wiley.

Harter, S., \& Pike, R. (1984). The pictorial scale of perceived competence and social acceptance for young children. Child Development, 55, 1969-1982. http://dx.doi.org/10.2307/1129772

Harter, S., Waters, P., \& Whitesell, N. R. (1998). Relational self-worth: Difference in perceived worth as a person across interpersonal context among adolescents. Child Development, 69, 756-766.

Hoffman, J. A. (2002). Psychological separation of late adolescents from their parents.

Hoffman, L. S. (1989). Developmental psychology today. New York.

Joseph, L. M. (1991, June-July). Gender Positioning of a Traditionally Male Dominant Product. Journal of Advertising Research, 31, 72-79.

Joseph, S. (1991). Change in Men's Housework and Child Care Time, 1965-1975. Journal of Marriage and the Family 48, 413-22.

Joseph, S. (1991). Connectivity and patriarchy among urban working class Arab families in Lebanon. Ethos 21(4), 452-484. http://dx.doi.org/10.1525/eth.1993.21.4.02a00040

Kagan, J., Rosman, B. S., Day, D., Albert, J., \& Phillips, W (1991). Information processing in the child: significance of analytic and reflective attitudes. Psychological Monographs, 1964, 78(1).

Kim, U., \& Choi, S. (1994). Individualistic, collectivism, and child development: A Korean perspective. In P. M. Greenfield \& R. R, Cocking (Eds.), Cross-cultural roots of minority child development (pp. 227-258).

Larson, L. E. (1994). System and subsystem perception of family roles. Journal of Marriage and the Family, 36, 123-138. http://dx.doi.org/10.2307/351002

Lee, G. (1990). Korean family and kinship. Seoul, Korea: Mineumsa.

Maccoby, E. E., \& Martin, J. A. (1983). Socialization in the context of the family: Parent-child interaction. In P. H. Mussen (Ed.), Handbook of child psychology:Vol.4.Socialization, personality, and social development, $1-101$.

Moore, R., \& Moschis, G. (1981). The role of family communication in consumer learning. Journal of Communication, 31, 42-51. http://dx.doi.org/10.1111/j.1460-2466.1981.tb00449.x

Moschis, P. G. (1985). The role of family communication in consumer socialization of children and adolescents. The Journal of Consumer Research, 11, 898-913. http://dx.doi.org/10.1086/209025 
Murphy, J. M. (1989). Separate and unequal: Women in the public address events. The National Forensic Journal, 1, 115-125.

Owens, S. Stryker, \& Goodman, N. (Eds.). Extending self esteem theory and research:Sociological and Psychological Currents, 400-436. Cambridge, UK: Cambridge University Press.

Rogers, D. (1980). Adolescent and Youth (5th ed.). New Jersey: Prentice Hall, Inc.

Shapiro, P., \& Penrod, S. (1986, September). Meta analysis of Facial Identification Studies. Psychological Bulletin, 100, 139-156. http://dx.doi.org/10.1037/0033-2909.100.2.139

Shavelson, J. R., \& Bolus, R. (1982). Self Concept: The Interplay of Theory and Methods. Journal of Educational Psychology, 74(1), 3-17. http://dx.doi.org/10.1037/0022-0663.74.1.3

Shek, D. T., \& Lee, C. M. (2005). Satisfaction and Quality dimensions of perceived parent adolescent communication among Chinese adolescents in Hong Kong. International Journal of Adolescent Medicine and Health, 18, 259-270.

Shields, S. M., \& Clark, A. K. (1997). Parental body build and the developmental progress of the offspring. Journal of Science, 132, 1555-1556.

Shuman, H. H. (2005). Infants born at risk, 389-411. New York: Spectrum.

Stoner, K., \& Kaiser, K. M. (1998). Personality Characteristics of MIS Project Teams: An Empirical Study and Action- Research Design. MIS Quarterly, 6(4), 43-60.

Wang, Y. (2007). A Cross-cultural and developmental Analysis of Self-Esteem in Cultural in Chinese and Western Children. Clinical Child and Family Psychology Rewiew, 4, 253-269. http://dx.doi.org/10.1023/A:1017551215413

Watson, C. L. (1995). Still a man's world. Berkeley, CA: University of California.

White, K. M., \& Speisman, J. C. (1987). Remaja. Terj. Maznah Ismail. Kuala Lumpur.

Williams, M. (2001). In whom we trust: Group membership as an affective context for trust development. Academy of Management Review, 26, 377-396. Furumo \& Pearson 59.

Williams, R. (1982). Beyond wives' family sociology: A method for analyzing couple data. Journal of Marriage and the Family, 44, 999-1008. http://dx.doi.org/10.2307/351459

Williams. R. (1991). Gender and God's Word: Another Look at Religious Fundamentalism and Sexism. Social Forces, 69, 1205-21. The Psychology of Gender. Eds. Anne E. Beall and Robert J. Sternberg. New York and London: Guilford Press, 55-98.

Wood, J. T. (1998). Gender Communication, and Culture. In L. A. Samovar, \& R. E. Porter (Eds.), Intercultural communication: A reader. Stamford, CT: Wadsworth.

Wood, W. (2001). Perceived sex differences in competence as a determinant of sex differences in interaction. Journal of Personality and Social Psychology, 50, 341-347. http://dx.doi.org/10.1037/0022-3514.50.2.341

Young, J. C., \& Shelley. (1997). Perceptions of Family Differention. Individuation and Self Esteem among Korean Adolescents. Journal of Marriage and The Family, Vol. 59, 451-462. $\mathrm{http}: / / \mathrm{dx}$.doi.org/10.2307/353482

Yusof, A. M. (2004). The relationship between family communication, self concept, and academic achievement of adolescents in some schools of Petaling Jaya, Malaysia. (Ed. D. thesis. Western Michigan University, 1984).

\section{Copyrights}

Copyright for this article is retained by the author(s), with first publication rights granted to the journal.

This is an open-access article distributed under the terms and conditions of the Creative Commons Attribution license (http://creativecommons.org/licenses/by/3.0/). 